\title{
Uma contribuição para a teoria de gênero
} A Contribution to Gender Theory

\author{
Marcos Claudio Signorelli' (iD) 0000-0003-0677-0121 \\ 'Universidade Federal do Paraná, Câmara de Saúde Coletiva, Matinhos, PR, Brasil. \\ 83260-000-camara.sc@ufpr.br
}

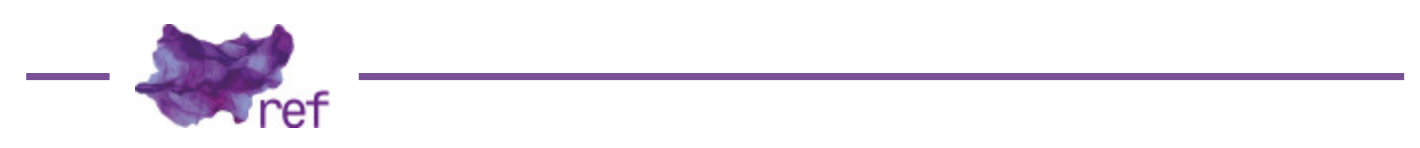

PEREIRA, Pedro Paulo Gomes.

Queer in the Tropics: Gender and Sexuality in the Global South.

Cham, Switzerland: Springer, 2019.

O livro Queer in the Tropics: Gender and Sexuality in the Global South, de Pedro Paulo Gomes Pereira (2019), publicado pela editora Springer, é o resultado de duas décadas de pesquisas e busca sintetizar os achados sobre gênero e sexualidade decorrentes das experiências pelas quais o autor passou no período. Conta com cinco capítulos e prefácios de Richard Miskolci e de Judith Butler.

No primeiro capítulo, "In and around life", emerge uma reflexão sobre a etnografia que Pereira realizou, no final da década de 1990, em uma ONG que abrigava pessoas com HIV pobres urbanos, excluídos, vidas precárias que formavam uma das paisagens originadas da relação estreita da extrema desigualdade socioeconômica do país e a epidemia de aids. Mapeando algumas das principais abordagens sobre o conceito de biopoder, o capítulo destaca uma tensão entre políticas que incentivam e buscam potencializar a vida e pessoas excluídas e deixadas para morrer.

O segundo capítulo, "Queer in the tropics", problematiza tanto a potência da teoria queer como seus possíveis limites, formulando indagações como: estaríamos diante de mais uma teoria do centro que viaja para as periferias (e que reinscreveria, noutras cores, esse divisor centroperiferia) para ser aplicada? Haveria possibilidade de o gesto político queer abrir-se para saberesoutros ou estaríamos presos dentro de um pensamento sem que nada de novo possamos propor ou vislumbrar? Essas questões ressoam também no capítulo seguinte, "Decolonial queer", no qual Pereira acompanha o itinerário geopolítico das teorias para delinear os contornos principais do encontro entre teoria queer e pensamento decolonial.

Em "On the Poetics of Incorporation", talvez o capítulo mais importante do livro, o autor se volta para o corpo. Ao analisar quais as articulações construiriam corpos, indaga: se os corpos são interfaces que vão ficando descritíveis quando aprendem a ser afetados por múltiplos elementos, colocados em movimento por entidades humanas e não humanas, quais seriam esses afetos, entidades e mediadores? A análise se centra na poética de invenção dos corpos de travestis.

Por fim, em "Judith Butler and the Pomba-gira", Pereira aborda a pressão que setores conservadores vêm exercendo contra as conquistas no campo de gênero e sexualidade. O autor coloca em xeque a oposição entre religiosidade e formas alternativas de vivência de sexualidade e de gênero. Indaga as possíveis brechas, as possibilidades de mediação e os limites de se pensar categorias fixas. Assinala que talvez o caminho seja o de aproximação à multiplicidade dos agentes e suas formas inauditas de agência, e à criatividade de suas poéticas. E, 
provocativamente, defende a necessidade de "torcer nosso pensamento"1 (Pedro Paulo Gomes PEREIRA, 2019, p. 97).

Pereira narra como encontrou as histórias e formulações das travestis, com suas performances e reconstruções corporais e com sua íntima vinculação com as religiões afro-brasileiras. Com as travestis, foi aprendendo que a invenção dos corpos pressupõe a sua reinvenção contínua. Encontramos então um pesquisador seduzido pelas reinvenções das travestis que o interpelaram, pela intensidade de seus interlocutores e interlocutoras e por suas conformações e multiplicidades. Afetado pelas poéticas das travestis sobre corporalidades e incorporações, Pereira se aproxima de suas filosofias, com as quais interpretam o mundo e suas próprias transformações corporais. $O$ autor mostra também como as travestis criam sofisticadas formas de agências para lidar com a exclusão desse poder que estabelece as categorias daquilo que pode entrar no mundo dos possíveis e que coloca seus corpos e subjetividades como impensáveis.

Diante dessas formulações, gostaria de ressaltar três aspectos que considero fundamentais sobre o livro.

1. O primeiro aspecto é a disponibilidade na qual Pereira se coloca para as interpelações de seus/suas interlocutores/as. O que surge em Queer in the tropics são reflexões produzidas em afecções e afetos que produzem posicionamentos. Pereira fala dos trópicos. Aqui a metáfora designa o Sul Global, mas, o Sul não é um conceito geográfico: compreende múltiplas trilhas já abertas historicamente que permaneceram em posição subalterna. Tal construção evita uma simples e mecânica oposição Norte e Sul que pode produzir apagamentos de outros aspectos geopolíiticos (como, por exemplo, as variações regionais no Brasil). O caminho escolhido, no entanto, não busca a autodeclaração identitária ou confissões fáceis, antes aposta na complexidade de sua narrativa. Butler percebeu essa densidade e assinala como as experiências moveram o autor, chegando a afirmar que o etnógrafo "cede o controle"2 (Judith BUTLER, 2019, p. xiii) e, não obstante às adversidades, "continua o acompanhamento"3 (BUTLER, 2019, p. xiii). As experiências afetam e provocam o "ceder o controle" (BUTLER, 2019, p. xiii) - a narrativa então revela as mudanças e as marcas dos afetos. Sempre partindo de suas pesquisas, o autor coloca-se no texto, deixando suas marcas; suas dúvidas contam sua história; suas posições se mostram nos movimentos conceituais. O posicionamento corpo-político do autor surge, então, nos trópicos, como quem aprende com e se transforma - encantando-se. Dessa forma, Pereira propõe que podemos, daqui dos trópicos, experimentar outros conceitos e experimentar-nos com outros conceitos.

2. No decorrer do livro, Pereira se aproxima de autoras e autores do Norte Global, dos textos da tradição anglo-saxã e francesa que dominam as ideias do social a partir da segunda metade do século XX. Por todo o percurso, busca subverter a máquina poderosa que faz com que apliquemos aqui o que fora formulado nos países centrais. Os capítulos vão ensaiando esse movimento usando termos como "romper e recuperar"4 (Ann Laura STOLER, 1995, p. 23) e "torcer as teorias"5 (PEREIRA, 2019, p. 97), e vão sugerindo que a questão não é uma simples crítica às teorias da Europa ou dos Estados Unidos. O problema é tomar essas teorias como simplesmente "aplicáveis"6 (PEREIRA, 2019, p. 7) a outras realidades. E a grande provocação, afirma o autor, é valer-se de seus conceitos, mas subvertendoOs, a partir das histórias partilhadas/entrelaçadas originadas no contexto (pós-)colonial. O esforço se direcionaria para alterar os conceitos, transformá-los de forma que possam abarcar mais, inverter e modificar os conceitos, transformando-os de tal forma e intensidade para que produzam algo novo. Claro que não basta adicionar as histórias locais e mexer, alerta o autor. É necessário que as experiências aqui dos trópicos afetem, no sentido forte do termo, o próprio quadro conceitual, e que, assim, ele possa se modificar, se transformar. O movimento de Pereira não é tecer uma crítica de fora, mas de elaborar uma forma afetiva de se aproximar. No processo de torcer, recuperar, as autoras e os autores falam de outro modo e mais e, assim, ficam maiores. Pereira se coloca, dessa maneira, distante de certa política do ressentimento que observa e esquadrinha as teorias de fora e, de forma rápida, propõe a distância e o esquecimento. Ao contrário, a proposta é de uma aproximação que se afeta e, no processo, permite as autoras e os autores dizerem mais. Essa proposta conduz ao "ceder o controle", pois supõe uma abertura propiciada pelos afetos - a possibilidade e a potência dos encantamentos. Pereira lembra que torcer o pensamento tem vários sentidos, entre eles, o de enroscar-se em movimentos espiralados, mas, também o de mudar a direção de. Envolver-se (enroscar-se) com as teorias, para dar-lhe nova direção.

3. Por fim, o livro traz uma importante contribuição à teoria de gênero. Talvez sendo este um dos pontos que o autor deveria ter se voltado (ou que possa se voltar em trabalhos futuros) com mais tempo e cuidado, possivelmente ressaltando seus achados e explorando-os com mais

\footnotetext{
'No original em inglês o autor utiliza "bending our way of thinking" (PEREIRA, 2019, p. 97).

${ }^{2}$ No original em inglês a autora utiliza "cedes control" (BUTLER, 2019, p. xiii).

${ }^{3}$ No original em inglês a autora utiliza "continues the accompaniment" (BUTLER, 2019, p. xiii).

${ }^{4}$ No original em inglês a autora utiliza "rupture/break and recover" (STOLER, 1995, p. 23).

${ }^{5}$ No original em inglês o autor utiliza "bending our way of thinking, including bending Butler's theory" (PEREIRA, 2019, p. 97).

" No original em inglês o autor utiliza "applicable" (PEREIRA, 2019, p. 7).
} 
detalhes. Ou seja, qual a teoria de gênero sai deste projeto? Butler, no prefácio da obra, é certeira no assunto e fala em uma "vasta contribuição para a teoria de gênero"7 (BUTLER, 2019, p. xiv) de Pereira. Não é pouca coisa uma das maiores pensadoras sobre gênero asseverar que há uma contribuição significativa para a teoria de gênero. Mas, qual seria? A resposta está na poética de invenção dos corpos das travestis nas religiões afro-brasileiras. Pereira nos conta, por exemplo, que muitas vezes as travestis têm uma Pomba-gira, que é incorporada e permanece uma característica desse gênero. No processo de incorporação alguém é afetado e transformado pela Pomba-gira, que se torna parte da própria formação e realização do gênero. O corpo que fora transformado por tecnologias, procedimentos, performances agora abre-se às entidades. Butler ressalta a dimensão dessa alteridade na qual o self não está mais fechado em si mesmo, mas sim definido por sua abertura à alteridade e pelas transformações que ocorrem como resultado dessa abertura. A contribuição de Pereira para teoria de gênero está nessa relação entre tradução e incorporação, pois o autor mostra como não são apenas entidades, corpos, práticas, instituições, tecnologias, mas que essa alteridade é em si uma característica transformadora. Não se trata de uma visão voluntarista que pressupõe que cada um pode mudar a si mesmo, nem apenas que as tecnologias atuam ou que as instituições imprimem sobre os corpos e subjetividades, mas sobretudo uma abertura aos Outros como constitutiva do próprio conceito de gênero.

Enfim, o/a leitor/a terá em mãos um livro provocativo, fruto de encantamentos de um pesquisador que vai mudando no decorrer das experiências e uma descrição encantada das formas inauditas de agência dos corpos dissidentes. Seus movimentos conceituais, suas formas de aproximação, seus afetos e interpelações talvez possam nos auxiliar a construir conversas coletivas - conversas que, como salientou Butler, talvez nos ajudem a não sermos pensáveis além das companhias.

\section{Referências}

BUTLER, Judith. "Foreword by Judith Butler: experiencing other concepts". Foreword. In: PEREIRA, Pedro Paulo Gomes. Queer in the Tropics: Gender and Sexuality in the Global South. Cham, Switzerland: Springer, 2019, p. xiii-xiv.

PEREIRA, Pedro Paulo Gomes. Queer in the Tropics: Gender and Sexuality in the Global South. Cham, Switzerland: Springer, 2019.

STOLER, Ann Laura. Race and the education of desire: Foucault's history of sexuality and the Colonial order of things. Durham: Duke University Press, 1995.

Marcos Claudio Signorelli (signorelli.marcos@gmail.com) é doutor em Saúde Coletiva (UNIFESP), Pós-doutor em Saúde Pública (La Trobe University, Australia), Docente da Graduação e Pós-Graduação em Saúde Coletiva da Universidade Federal do Paraná (UFPR). Líder do Grupo Interdisciplinar de Pesquisas sobre Território, Diversidade e Saúde (TeDiS/CNPq). Coordenador do GT de Saúde da População LGBTI+ da Associação Brasileira de Saúde Coletiva (ABRASCO).

\section{COMO CITAR ESSE ARTIGO DE ACORDO COM AS NORMAS DA REVISTA}

SIGNORELLI, Marcos Claudio. "Uma contribuição para a teoria de gênero". Revista Estudos Feministas, Florianópolis, v. 28, n. 3, e68402, 2020.

\section{CONTRIBUIÇÃO DE AUTORIA}

Não se aplica.

\section{FINANCIAMENTO}

Não se aplica.

\section{CONSENTIMENTO DE USO DE IMAGEM}

Não se aplica.

\section{APROVAÇÃO DE COMITÊ DE ÉTICA EM PESQUISA}

Não se aplica.

${ }^{7}$ No original em inglês a autora utiliza "vast contribution to gender theory" (BUTLER, 2019, p. xiv). 


\section{CONFLITO DE INTERESSES}

Não se aplica.

\section{LICENÇA DE USO}

Este artigo está licenciado sob a Licença Creative Commons CC-BY International. Com essa licença você pode compartilhar, adaptar, criar para qualquer fim, desde que atribua a autoria da obra.

\section{HISTÓRICO}

Recebida em 03/11/2019

Aprovada em $17 / 02 / 2020$ 